\title{
RESIDENTS' SATISFACTION WITH THE INDOOR ENVIRONMENTAL QUALITY OF RE-ENGINEERED AFFORDABLE HOUSING SCHEMES IN MALAYSIA
}

\author{
Syahrul Nizam Kamaruzzaman ${ }^{1 *}$, Atikah Razali ${ }^{1}$, Emma Marinie Ahmad Zawawi ${ }^{2}$, \\ Siti Arni Basir ${ }^{3}$, Mike Riley ${ }^{4}$ \\ ${ }^{1}$ Building Surveying Department, Faculty of Built Environment, University of Malaya, Kuala Lumpur \\ 50603, Malaysia \\ ${ }^{2}$ Faculty of Architecture, Planning \& Surveying, University Technology MARA, Shah Alam, Selangor \\ 40450, Malaysia \\ ${ }^{3}$ Department of Siasah Syar'iyyah Academy of Islamic Studies, University of Malaya, Kuala Lumpur \\ 50603, Malaysia \\ ${ }^{4}$ School of Built Environment, Liverpool John Moores University, Liverpool L3 5UA, United Kingdom
}

(Received: October 2017 / Revised: January 2018 / Accepted: March 2018)

\begin{abstract}
Malaysia is currently focusing on providing affordable housing all over the country, as part of the plan to tackle the problem of the rising costs of house ownership due to reasons such as the economic crisis and land limitations. However, a limited number of methodical studies have been conducted on residents' feedback on the indoor environment of affordable housing. Indoor Environmental Quality (IEQ) is an important aspect of occupants' wellbeing, as it affects their health and productivity. Therefore, evaluating residents' feedback on IEQ is an important step in gauging building performance and conditions. In addition, the health and productivity of residents needs to be evaluated in order to identify the effect of IEQ on them. A questionnaire survey was used to achieve the study objectives and to gain access to the respondents' views and feedback. The pilot questionnaire study was conducted at two housing apartments in Kuala Lumpur, Malaysia, and the data collected were evaluated and analyzed using SPSS software. The outcome of this pilot study is significant, as it shows the residents' dissatisfaction level towards IEQ factors such as noise, glare and privacy, and other aspects of IEQ that are important, such as ventilation. Additionally, it has been found that the IEQ of the residents does affect their health and productivity. It is anticipated that the outcome of this study will serve as an indicator of building performance improvements needed to achieve a better indoor environment quality for affordable housing in Malaysia.
\end{abstract}

Keywords: Affordable housing; Indoor Environmental Quality; Satisfaction

\section{INTRODUCTION}

Affordability is mainly defined as the relationship between a household's expenditure and income (Musa et al., 2011; Menshawy et al., 2016). Affordable housing schemes have become a common method to deal with housing issues in the various housing markets in Malaysia. Affordability is perceived to be related to income, housing costs, housing availability, employment, maintenance of the existing affordable housing stock, and patterns of new construction. Affordable housing not only focuses on providing affordable shelter, but also on

*Corresponding author's email: syahrulnizam@um.edu.my.com, Tel: +603-7367-6833, Fax: +603-7967-5713

Permalink/DOI: https://doi.org/10.14716/ijtech.v9i3.826 
the quality of life of the occupants living in the dwelling. In the modern environment, housing policies have several objectives, and are rarely confined to a box labelled 'housing'. They encompass, for example, macroeconomic and environmental objectives and reach into the territory of policies that come under such headings as 'health', 'social exclusion' and 'urban regeneration' (Winston, 2008; Houk et al, 2015). According to Baqutaya et al. (2016), the policy on housing is not only for housing access and affordability, but is also due to the effect of housing expenditure on inflation, growth and economic stability.

Over the years, the Malaysian government has been providing affordable housing to help solve the housing issues in Malaysia, and according to their Eleventh Malaysian Plan (2016-2020), they are planning to increase the quantity of affordable housing and introduce housing schemes such as MyHome and RR1M. This is a positive development in Malaysia, not only for the welfare of the citizens, but also for the economy of the country and its developers. However, the increase in the quantity of affordable housing does not guarantee improvements in the quality of the indoor environment (IEQ), which commonly affects people's comfort, health and productivity (Haghighat \& Donnini, 1999; Lai et al., 2009; Frontczak \& Wargocki, 2011; Al Horr et al., 2016). For example, one of the aspects of IEQ that influences residents' well-being is the thermal comfort of the space, such as temperature and ventilation (Persily, 2015; Nimlyat \& Kandar 2015).

Despite the fact that the newly built buildings and housing are deemed to have satisfied the recommended standards, however, there are still complaints regarding their indoor environmental quality of the building and hosuing in Malaysia. The World Health Organization (WHO) recorded that in $198430 \%$ of ccurring buildings were subject to complaints concerning their IEQ. Dr Judith H. Heerwagen, an environmental psychologist, (as cited in Kolleeny, 2003) points out that several factors, such as exposure to daylight, air quality, temperature, odors, noise, ergonomics, opportunities for social gatherings, and relaxation, and exercise, affect residents' productivity and well-being. The Environmental Protection Agency (1991) labelled this effect as sick building syndrome (SBS), whereby occupants experience acute health problems and discomfort only when they are in the building or space, and based on the time spent in the building. Therefore, buildings and space affect the well-being and productivity of the occupants residing in them. Hence, it is essential that the indoor environment of affordable housing is adequate for the health and productivity of the residents.

Hashim (2010) points out that no specific studies or research have been conducted on affordable building, especially regarding the issues arising around it. Furthermore, the Malaysian government plans to continue the building of affordable housing in Malaysia in order to satisfy the demand for it, as well as to overcome the housing issues in the country. Therefore, it is important to investigate the IEQ of affordable housing in Malaysia to improve its quality. Moreover, it is critical that sustainable development results not just in resource conservation, but also in increasing productivity and residents' well-being. This study hopes to inform the design community on residents' perception of affordable housing performance based on the IEQ criteria. It will add to the growing body of research on sustainable design and residents' perception of indoor environmental quality.

\section{AFFORDABLE HOUSING SCHEMES IN MALAYSIA}

The Malaysian government has introduced several schemes and initiatives to provide affordable housing for the population. They allocated a budget for it in their Tenth Malaysia Plan (20112015) and Eleventh Malaysia Plan (2016-2020). In the latter, they intend to construct a total of 653,000 affordable housing units under programmes such as PBR, PR1M and PPAIM. Table 1 summarises the number of units for each programme. 
Table 1 Targets for public affordable housing

\begin{tabular}{lc}
\hline Programme & Housing Units \\
\hline PBR & 47,000 \\
PPR & 50,000 \\
PR1MA & 380,000 \\
PPA1M & 88,000 \\
RMR1M & 55,000 \\
RUMAWIP & 33,000 \\
\hline TOTAL & $\mathbf{6 5 3 , 0 0 0}$ \\
\hline
\end{tabular}

Furthermore, the government has developed several strategies for affordable housing to efficiently and productively fulfil the Eleventh Malaysia Plan. This plan used a Blue Ocean Strategy (BOS) formulation tool called the strategy canvas. It is a diagnostic and action framework to visualize the strategies for the Malaysia Plan. As stated in the Eleventh Malaysia Formula document, the strategy canvas (as shown in Figure 1) portrays the current situation against the new strategic direction that will be taken by the government. The strategy canvas represents the strategies developed by the government for efficient affordable housing and productivity in order to fulfil the Eleventh Malaysia Plan. The canvas highlights the parameters that need to be reduced, eliminated, raised or created in order to achieve an effective plan strategy.

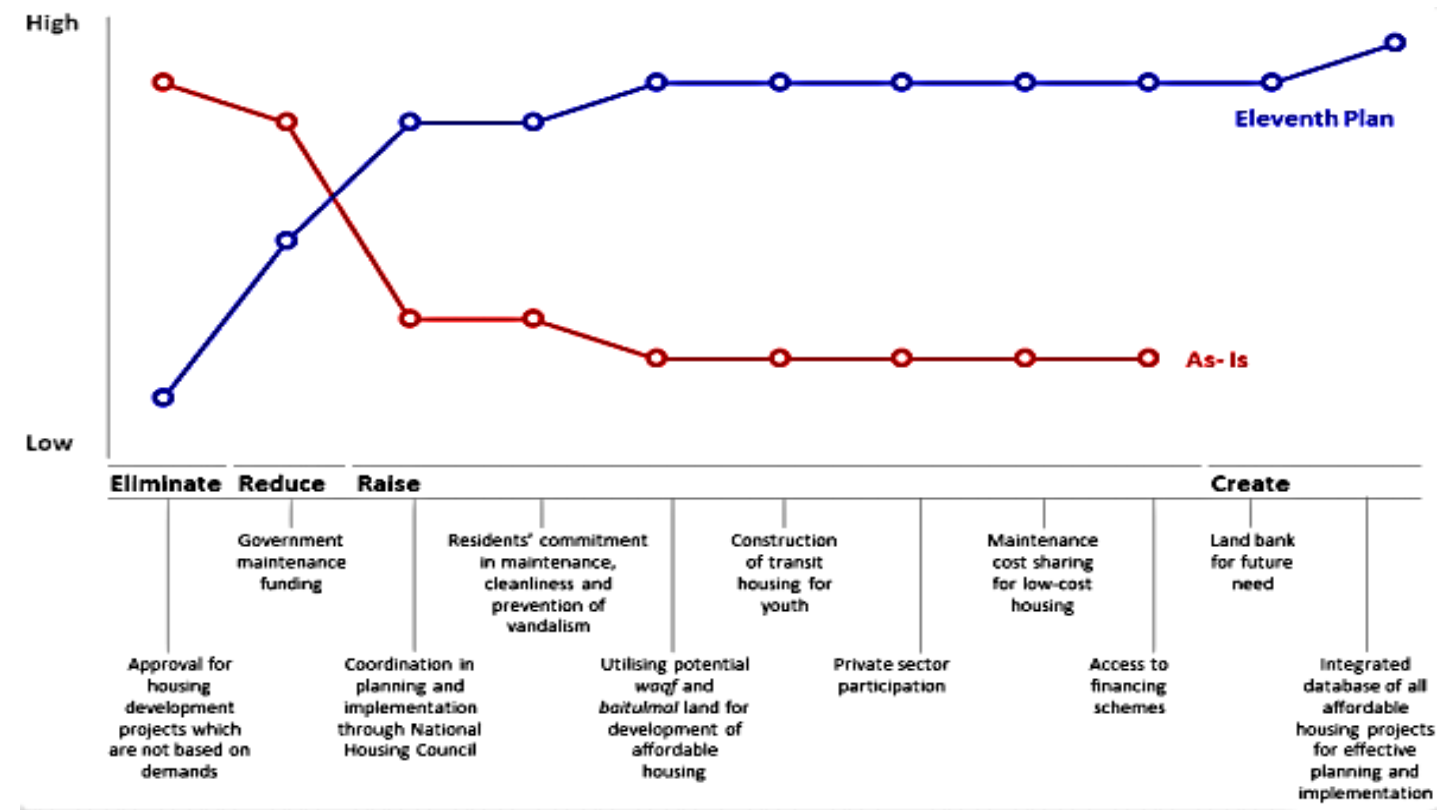

Figure 1 Strategy canvas for providing adequate and quality affordable housing (Plan, 2015)

\section{INDOOR ENVIRONMENTAL QUALITY CATEGORY}

The Centers for Disease Control and Prevention (CDC) (2013) define IEQ as the quality of the building environment that relates to the health and well-being of the occupants. Kolleeny (2003) stated that Heerwagen points out that elements of IEQ affect residents' productivity and well-being, while the Institute of Medicine (IOM) (2011) agrees that IEQ should be an area of consideration as it affects the comfort and health of residents. Moreover, scholars such as Crump (2011) and Kamaruzzaman et al. (2011) concur that IEQ has a significant impact on residents' health and productivity. 
There are four main categories of IEQ. The Leadership in Energy and Environmental Design (LEED) listed indoor air quality (IAQ), daylight and views, acoustic comfort and thermal comfort as the categories. The industries and organizations from other various countries, such as the Building Research Establishment Environmental Assessment Method (BREEAM) by the Building Research Establishment (BRE) in the United Kingdom also agree on these four categories. Furthermore, in Malaysia the Green Building Index (GBI) has also categorized IEQ as thermal comfort, acoustic comfort, visual comfort and IAQ. Table 2 summaries the categories of IEQ.

Table 2 Categories of IEQ according to the industries and organizations around the world

\begin{tabular}{lll}
\hline \multicolumn{1}{c}{ LEED } & \multicolumn{1}{c}{ BREEAM } & \multicolumn{1}{c}{ GBI } \\
\hline Indoor air quality (IAQ) & Indoor air quality (IAQ) & Indoor air quality (IAQ) \\
Daylight and Views & Visual Comfort & Visual comfort \\
Acoustic Comfort & Acoustic Comfort & Acoustic Comfort \\
Thermal Comfort & Thermal Comfort & Thermal comfort \\
\hline
\end{tabular}

Scholars such as Nimlyat and Kandar (2015) and Martellotta et al. (2016) also agree that thermal comfort, indoor air quality (IAQ), visual comfort and acoustic comfort are factors which affect IEQ. Kolleeny (2003) cites Heerwagen, who suggested that exposure to daylight, air quality, temperature, noise and odors influences occupants' productivity and well-being. Nimlyat and Kandar (2015) group temperature in the thermal comfort category; daylight in that of visual comfort; noise in the acoustic comfort category, and odour and air quality in the IAQ category. Other scholars, such as Martellotta et al. (2016) and Sarbu and Sebarchievici (2013), agree on the grouping and add elements such as relative humidity in the thermal comfort category, and ventilation in the IAQ category. In conclusion, the main categories of IEQ that need to be taken into account are IAQ, visual comfort, acoustic comfort and thermal comfort. The four categories need to be fulfilled in order to provide an indoor environment conducive to residents.

\section{METHODOLOGY}

\subsection{Study Design}

For this pilot study, two affordable housing apartment area, located in Kuala Lumpur were selected and labelled as Apartment A and Apartment B. Both apartments are 17 stories high and are located close to public amenities and public transport, such as bus stations, LRT stations, and commuter stations. Both types of apartment consist of three bedrooms and two bathrooms; the units in Apartment A have floor areas ranging from 650 sq. ft. to 750 sq. ft., while those in Apartment B range from 616 sq. ft. to 650 sq. ft.

\subsection{Questionnaire Survey}

The method used to conduct the pilot study was questionnaire survey. The convenience sampling method was used to distribute a total of 15 sets of questionnaires on each site. One of the purposes of the pilot study was to establish the clarity of the questionnaire as well as to improve it for the main study. Therefore, the number of targeted participants was limited. The survey was divided into three sections: Section A, Section B and Section C. Section A asked about the demographics and backgrounds of the respondents, Section B their health condition, while Section C asked questions about the respondents' level of satisfaction with the IEQ factors, as well as about the level of importance of each factor. The questionnaire used a Likert 5-point scale in Section B and Section C, as shown in Table 4. 
Table 3 Case study details

\begin{tabular}{|c|c|c|}
\hline Apartment Area & Apartment (A) & Apartment (B) \\
\hline Location & $\begin{array}{l}\text { Bandar Sri Permaisuri, Cheras, Kuala } \\
\text { Lumpur }\end{array}$ & $\begin{array}{l}\text { Taman Tasik Permaisuri, Cheras, Kuala } \\
\text { Lumpur }\end{array}$ \\
\hline Building age & $\sim 10$ years (as of 2017) & $\sim 8$ years (as of 2017) \\
\hline Floor area & 650 to $750 \mathrm{sqft}$ & 616 to $650 \mathrm{sqft}$ \\
\hline Number of Blocks & 2 & 3 \\
\hline Number of Units & 17 stories with 260 units & 17 stories with 144 \\
\hline Space & 3 bedrooms and 2 bathrooms & 3 bedrooms and 2 bathrooms \\
\hline Amenities & $\begin{array}{l}\text { - } 1.9 \mathrm{~km} \text { walk to Salak Selatan LRT } \\
\text { Station. } \\
\text { - } 1.6 \mathrm{~km} \text { walk to Bandar Tun Razak } \\
\text { LRT Station. } \\
\text { - } 1.9 \mathrm{~km} \text { walk to Salak Selatan } \\
\text { Commuter Station. } \\
\text { - } 1.3 \mathrm{~km} \text { walk to bus stop and taxi } \\
\text { stand. } \\
\text { - } 1 \mathrm{~km} \text { to commercial hub. } \\
\text { - } 7 \mathrm{~km} \text { to Seremban Expressway; } 13 \\
\mathrm{~km} \text { to KESAS Expressway. }\end{array}$ & $\begin{array}{l}\text { - } 1.5 \mathrm{~km} \text { walk to Salak Selatan LRT } \\
\text { Station. } \\
\text { - } 1.7 \mathrm{~km} \text { walk to Bandar Tun Razak LRT } \\
\text { Station. } \\
\text { - } 1.3 \mathrm{~km} \text { walk to Salak Selatan } \\
\text { Commuter Station. } \\
\text { - } 1 \mathrm{~km} \text { walk to bus stop and taxi stand. } \\
\text { - } 130 \mathrm{~m} \text { to commercial hub. } \\
\text { - } 4 \mathrm{~km} \text { to } 10 \mathrm{~km} \text { from Middle Ring Road } \\
\text { II (MRR2) highways. }\end{array}$ \\
\hline
\end{tabular}

Table 4 Likert 5-point scale indicator

\begin{tabular}{clll}
\hline \multirow{2}{*}{ Scale } & \multirow{2}{*}{ Section B } & \multicolumn{2}{c}{ Section C } \\
\cline { 3 - 4 } & & Satisfaction Level & Importance Level \\
\hline 1 & Never & Extremely Dissatisfied & Most Unimportant \\
2 & Rarely & Dissatisfied & Unimportant \\
3 & Sometimes & Neutral & Neutral \\
4 & Often & Satisfied & Important \\
5 & Very Often & Extremely Satisfied & Most Important \\
\hline
\end{tabular}

The questionnaire was distributed by hand to the participants at the study sites, with a sample size of $(n=30)$, in January 2017. All thirty questionnaires were returned, which represented a $100 \%$ response rate.

\section{RESULTS AND DISCUSSION}

\subsection{Respondent Characteristics}

Table 5 shows the characteristics of the respondents in Apartment A and Apartment B. Both apartments had a similar distribution in terms of gender, with $60 \%$ of the respondents being female and $40 \%$ male. The majority of the respondents were in the age range 20-29 years old, followed by 30-39 years old. No respondents were in the 40-49 year old or 50-59 year old groups in Apartment B. 87\% of the respondents from Apartment A and 93\% from Apartment B were tenants. Furthermore, $73 \%$ of the respondents from Apartment A live in units of up to five people, while only $27 \%$ of the household sizes were between six to ten people per unit. On the other hand, $60 \%$ of the respondents in Apartment B lived in units with up to 5 people per unit, with the remaining $40 \%$ of the household sizes being 6 to 10 people per unit.

$86 \%$ of the respondents had lived in Apartment A for up to 5 years, $7 \%$ for 6 to 10 years and the other $7 \%$ for 10 to 15 years. In Apartment B, the majority of the residents, 93\%, had lived there for up to 5 years, while $7 \%$ had been there for 6 to 10 years.

\subsection{Residents' Health Condition}

Table 6 shows the health condition of the occupants living in the affordable housing units. There were significant differences between Apartment A and Apartment B. 94\% of the 
Table 5 Respondents' characteristics

\begin{tabular}{|c|c|c|c|}
\hline Location & & Apartment A & Apartment B \\
\hline \multirow{3}{*}{ Gender } & Male & $40 \%$ & $40 \%$ \\
\hline & Female & $60 \%$ & $60 \%$ \\
\hline & Total & $100 \%$ & $100 \%$ \\
\hline \multirow{5}{*}{ Age (years) } & $20-29$ & $60 \%$ & $80 \%$ \\
\hline & $30-39$ & $20 \%$ & $20 \%$ \\
\hline & $40-49$ & $13 \%$ & $0 \%$ \\
\hline & $50-59$ & $7 \%$ & $0 \%$ \\
\hline & Total & $100 \%$ & $100 \%$ \\
\hline \multirow{3}{*}{ Ownership status } & Owner & $13 \%$ & $7 \%$ \\
\hline & Tenant & $87 \%$ & $93 \%$ \\
\hline & Total & $100 \%$ & $100 \%$ \\
\hline \multirow{3}{*}{ Household size (persons) } & $0-5$ & $73 \%$ & $60 \%$ \\
\hline & $6-10$ & $27 \%$ & $40 \%$ \\
\hline & Total & $100 \%$ & $100 \%$ \\
\hline \multirow{4}{*}{ Period of residency (years) } & $0-5$ & $86 \%$ & $93 \%$ \\
\hline & $6-10$ & $7 \%$ & $7 \%$ \\
\hline & $11-15$ & $7 \%$ & $0 \%$ \\
\hline & Total & $100 \%$ & $100 \%$ \\
\hline
\end{tabular}

residents in Apartment A had experienced changes in their health while living in their unit, while $6 \%$ had experienced no changes. On the other hand, in Apartment B there were significant differences, with $33 \%$ experiencing improved health, $20 \%$ unchanged health, and the remaining $47 \%$ experiencing a worsening in their health condition. Secondly, $47 \%$ of respondents from Apartment A had consulted a doctor for symptoms related to SBS, while the figure for Apartment B was 53\%.

Table 6 Residents' health condition and hours spent per day in the unit

\begin{tabular}{llcc}
\hline & & Apartment A & Apartment B \\
\hline \multirow{2}{*}{ Seen Doctor } & Yes & $67 \%$ & $53 \%$ \\
& No & $33 \%$ & $47 \%$ \\
\cline { 2 - 4 } & Total & $100 \%$ & $100 \%$ \\
\hline \multirow{3}{*}{ Health Condition } & Improving & $47 \%$ & $33 \%$ \\
& Worsening & $47 \%$ & $47 \%$ \\
& No Change & $6 \%$ & $20 \%$ \\
\hline \multirow{3}{*}{ Times spent in the } & Total & $100 \%$ & $100 \%$ \\
unit (hours/day) & $0-5$ & $73 \%$ & $13 \%$ \\
& $6-10$ & $27 \%$ & $47 \%$ \\
& $11-15$ & $0 \%$ & $27 \%$ \\
& $16-20$ & $0 \%$ & $13 \%$ \\
\hline
\end{tabular}

There were significant differences between the time spent daily in the units in both apartments. The majority of the respondents spent up to 5 hours $(73 \%)$ or at most 10 hours $(27 \%)$ in their unit. On the other hand, the respondents in Apartment B spent more time in their unit compared to those Apartment A, where the majority spent up to 10 hours (47\%) in their dwelling, followed by 15 hours (27\%). The remaining 26\% of the respondents in Apartment B spent either up to 5 hours $(3 \%)$ or up to 20 hours $(13 \%)$ in their apartment. Interestingly, $73 \%$ and $13 \%$ of the respondents in Apartments $\mathrm{A}$ and $\mathrm{B}$, respectively spent less than 5 hours in their 
apartment. External factors such as job requirements might contribute to the time residents spent in their unit.

\subsubsection{Health symptoms experienced by the respondents}

Sick building syndrome (SBS) is the term used by the EPA (1991) to describe a condition where an individual experience an acute health condition or discomfort. However, these symptoms only occur when the occupant is in a space or a building. In 1984, WHO recorded complaints made by the occupants of a building regarding the discomfort they were experiencing. They discovered that $30 \%$ of remodeled buildings were prone to complaints. They also recorded occasional symptoms of SBS such as eye, nose and throat irritation, headaches and itchiness. Additionally, Vardoulakis et al. (2015) and Martellotta et al. (2016) state that besides physical health conditions, stress and anxiety are two of the symptoms of SBS.

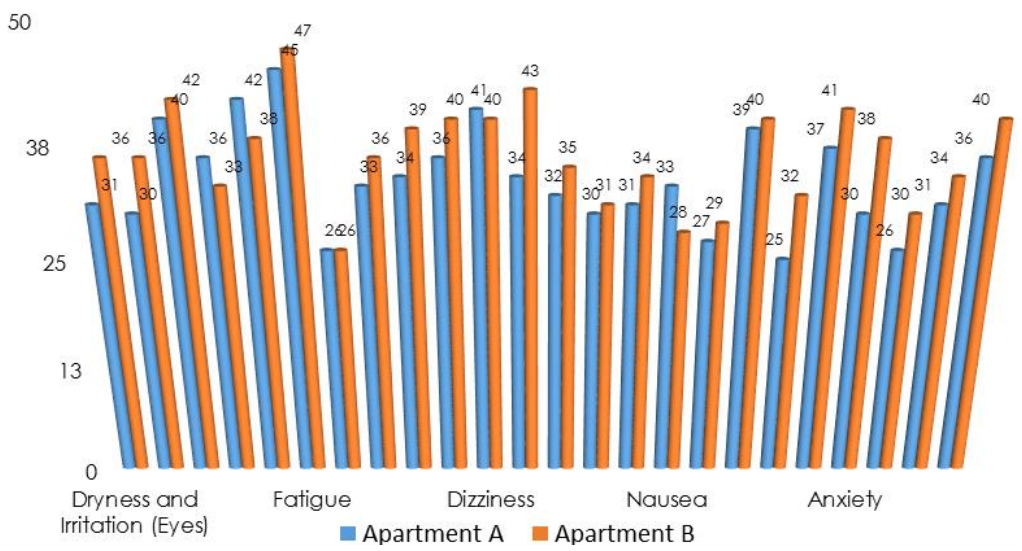

Figure 2 Total health conditions scores of the residents in Apartments A and B

The respondents were asked about the frequency of the SBS symptoms experienced in Section B. Figure 2 shows the total health symptom scores of the residents in Apartments A and B. Based on the figures, the residents in Apartment B suffered from more health symptoms than those in Apartment A. The most severe symptoms in the residents in both apartments were fatigue, dryness and irritation of the throat, dizziness, and sleep disturbance. The most severe conditions occuring in Apartment A were headaches, skin dryness and itchiness, and nausea, while sneezing, stuffy noses, stress and anxiety were those suffered in Apartment B. This shows that both apartments do not only manifest physical health problems, but also mental health conditions.

There are other external factors that influence the symptoms experienced by the occupants, such as work stress or seasonal changes that contribute to coughing and sneezing, but it is arguable that the indoor environment in their apartment units also contributes to the symptoms. Frontczak and Wargocki (2011), Nimlyat and Kandar (2015), Abdul-Wahab et al. (2015), and Al Horr et al. (2016) suggest that these symptoms occur because of the inadequacy of IEQ in housing units. Moreover, one of the factors that contributes to symptoms is the location of the apartments. Both apartments are located near the main highway, and Apartment A is located close to a gas station. Consequently, the locations of the apartments are prone to a high density of carbon monoxide and smoke. Furthermore, as Apartment A is close to a gas station, this influences the odor around the apartments. Hence, both apartments are located in noisy and air polluted environments. These outdoor environments influence the indoor environment of the apartments, as air flows into the building through openings in the building envelope, such as windows, trickle vents and louvres (Heiselberg et al., 2001). Additionally, both of the sites are located near public amenities such as commercial hubs and shopping lots, which allow public 
circulation around the apartments. As Turunen et al. (2014), Willich et al. (2006) and Pekkonen et al. (2015) suggest, higher density transportation and public access areas are prone to dust, particulate matter, and gas and noise pollution. These consequently affect the health of the occupants.

\subsection{Residents' Satisfaction with IEQ Factors}

Table 7 indicates the degree of satisfaction of the residents with the IEQ of their housing units. The average satisfaction level mean value for Apartment A is 3.21667, while for Apartment B it is 3.506655; a value greater than the average represents satisfaction, while a value lower than the average represents dissatisfaction towards the IEQ of the apartments. Respondents from Apartment A were dissatisfied with four factors, and those from Apartment B with five. More importantly, both apartments were dissatisfied with the same three factors: privacy, glare level, and noise level in their units.

Table 7 Residents' satisfaction level with IEQ factors

\begin{tabular}{lcccc}
\hline & \multicolumn{4}{c}{ Satisfaction Level } \\
\cline { 2 - 5 } \multicolumn{1}{c}{ Factors } & \multicolumn{2}{c}{ Apartment A } & \multicolumn{2}{c}{ Apartment B } \\
\cline { 2 - 5 } & Mean & Rank & Mean & Rank \\
\hline Amount of air movement & 3.3333 & 9 & 3.6 & 11 \\
Amount of daylight & 3.7333 & 19 & 3.8667 & 18 \\
Amount of electric lighting & 3.4667 & 15 & 3.3333 & 5 \\
Amount of space & 3.4667 & 16 & 3.7333 & 14 \\
Attractiveness of the unit & 3.4667 & 17 & 3.5333 & 10 \\
Colors of the unit & 3.6667 & 18 & 3.2667 & 4 \\
Control over the local environment & 3.2667 & 5 & 3.7333 & 13 \\
Distance from window & 3.9333 & 20 & 3.8667 & 19 \\
Freshness of the unit & 3.2667 & 6 & 3.5333 & 6 \\
Glare level around the rooms & 3.2667 & 7 & 3.5333 & 7 \\
Glare level in the unit & 2.0667 & 2 & 2.3333 & 1 \\
Health when in the unit & 3.2667 & 8 & 3.9333 & 20 \\
Humidity level in the unit & 3.3333 & 10 & 3.8 & 16 \\
Noise level & 2.5333 & 3 & 2.9333 & 3 \\
\hline Odor in the unit & 3.3333 & 11 & 3.8 & 17 \\
Outward appearance of the unit & 3.4 & 14 & 3.5333 & 9 \\
\hline Privacy in the unit & 1.6667 & 1 & 2.8667 & 2 \\
\hline Unit in general & 3.2 & 4 & 3.8 & 15 \\
Unit temperature & 3.3333 & 12 & 3.6 & 12 \\
Ventilation & 3.3333 & 13 & 3.5333 & 8 \\
\hline Average mean & 3.21667 & & 3.506655 \\
\hline
\end{tabular}

The respondents were not satisfied with the acoustic and visual comfort of their units. The location of the apartments might be the cause of this dissatisfaction, while household size might contribute to their dissatisfaction with privacy in the units. This is because $27 \%$ of respondents in Apartment A and 40\% of those from Apartment B live in groups of six to ten people in the three bedroom and two bathroom units. Furthermore, the household size could also contribute to the dissatisfaction with noise level.

\subsection{Resident' Perspective on the Importance of IEQ Factors}

Table 8 shows the level of importance of the IEQ factors according to the respondents. The average mean values for Apartment A and Apartment B are 3.9634 and 4.28667, respectively. The values above the average mean indicate the important factors, while those below the average indicate the less important factors from the perspective of the respondents.

From the survey findings, residents from both apartments indicated that ventilation, air movement and health were the three most important aspects of IEQ. Ventilation and air 
movement, according to Nimlyat and Kandar (2015), fall under the same category, namely IAQ.

Table 8 Importance factors of IEQ from the perspective of the residents

\begin{tabular}{lcccc}
\hline & \multicolumn{4}{c}{ Level of Importance } \\
\cline { 2 - 5 } \multicolumn{1}{c}{ Factors } & \multicolumn{2}{c}{ Apartment A } & \multicolumn{2}{c}{ Apartment B } \\
\cline { 2 - 5 } & Mean & Rank & Mean & Rank \\
\hline Amount of air movement & 4.2667 & 1 & 4.6 & 3 \\
Amount of daylight & 4.1333 & 7 & 4.2667 & 13 \\
Amount of electric lighting & 3.7333 & 14 & 4.3333 & 11 \\
Amount of space & 4.2 & 6 & 4.4 & 9 \\
Attractiveness of the unit & 3.6667 & 18 & 3.7333 & 19 \\
Colors of the unit & 3.6667 & 19 & 3.5333 & 20 \\
Control over the local environment & 4.0667 & 9 & 4.4667 & 6 \\
Distance from window & 4.2 & 4 & 4.1333 & 14 \\
Freshness of the unit & 4.0667 & 10 & 4.4667 & 7 \\
Glare level around the rooms & 3.4 & 20 & 4.0667 & 15 \\
Glare level in the unit & 3.8667 & 12 & 3.8 & 18 \\
\hline Health when in the unit & 4.2667 & 2 & 4.8 & 1 \\
Humidity level in the unit & 3.8667 & 13 & 4.0667 & 16 \\
Noise level & 3.7333 & 15 & 4.4667 & 8 \\
Odor in the unit & 4.1333 & 8 & 4.4 & 10 \\
Outward appearance of the unit & 3.7333 & 16 & 4.0667 & 17 \\
Privacy in the unit & 4.2 & 5 & 4.6 & 4 \\
Unit in general & 3.7333 & 17 & 4.5333 & 5 \\
Unit temperature & 4.0667 & 11 & 4.3333 & 12 \\
Ventilation & 4.2667 & 3 & 4.6667 & 2 \\
\hline Average mean & 3.96334 & & & 4.28667 \\
\hline
\end{tabular}

Ventilation and air movement in the units are closely related to natural ventilation; the outside air will move through the openings in the building envelope to provide fresh air, as well as to replace hot air inside the units. However, natural ventilation will be ineffective if the quality of the outside environment is poor. For example, the openings in both apartments increase the noise level due to the traffic on the highway. Additionally, the surrounding air quality contains particulate matters such as carbon monoxide, and the airflow in Apartment A, which faces a gas station, will bring strong odors into the units. Therefore, the quality of air surrounding buildings is important, as it will influence the quality of air inside. Consequently, without ventilation, the hot air trapped inside the enclosed space will cause suffocation and headaches amongst occupants. Thus, in order to overcome this issue, mechanical ventilation needs to be installed in both apartments.

\section{CONCLUSION}

The Malaysian government has been taking initiatives to overcome the housing issues occuring in Malaysia by providing affordable housing for the citizens. This has resulted in an increasing demand for affordable housing units; consequently, the government plans to provide approximately 653,000 units, according to their Eleventh Malaysia Plan (2016-2020). Despite this positive development, the quality of this affordable housing is still unclear, specifically regarding the indoor environment. Therefore, this paper aimed to explore residents' satisfaction level with the IEQ of their affordable housing, with the intention to provide an insight into the quality of the indoor environment and the factors that should be taken into consideration in future development of affordable housing. The study approached respondents with a questionnaire in two apartments in Kuala Lumpur in order to gauge their perspective on their health condition, satisfaction level, and the level of importance of the IEQ factors. 
The respondents from both apartments had the same distribution in terms of gender; however, other characteristics such as age and household size varied. From the questionnaire, it was found that the residents in Apartment A and Apartment B experienced sick building syndrome (SBS) symptoms. The most severe symptoms experienced by both sets of residents were fatigue, dryness and irritation of the throat, dizziness and sleep disturbance. Furthermore, those in Apartment B suffered psychological health problems such as stress and anxiety. Those living in both Apartment A and Apartment B were dissatisfied with the noise level and privacy, as well as the glare in their unit. More importantly, they rated ventilation, air flow, health and privacy in their unit as the important IEQ factors from their perspective. Their dissatisfaction, as well as the importance of the IEQ factors, might be influenced by the surrounding of the apartments, as both are located in areas of high transportation density and high circulation in public access areas. These two contributing factors eventually influence the indoor environment of the units.

Based on this pilot study, the quality of IEQ in Malaysia is inadequate and needs to be improved in future development of affordable housing. Insufficient IEQ contributes to residents' discomfort and exposes them to severe sickness and symptoms, reducing their productivity and health. Several important IEQ factors such as ventilation need to be stressed and considered during the design process of housing. Furthermore, other contributing factors such as location also need to be considered during the development of affordable housing in Malaysia. In conclusion, it is expected that the main study will show that the health of the residents in the affordable housing units is affected by the IEQ of their apartments, due to SBS symptoms. Moreover, it is anticipated that there are residents who are dissatisfied with several IEQ factors and their effect on them. The external factors that influence the IEQ should also be identified in the main study.

\section{ACKNOWLEDGEMENT}

This research was funded and supported by UMRG (RP015E-15SUS), University Malaya, Research Grant, Sustainability Science Research Cluster.

\section{REFERENCES}

Abdul-Wahab, S.A., En, S.C.F., Elkamel, A., Ahmadi, L., Yetilmezsoy, K., 2015. A Review of Standards and Guidelines Set by International Bodies for the Parameters of Indoor Air Quality. Atmospheric Pollution Research, Volume 6(5), pp. 751-767

Al Horr, Y., Arif, M., Katafygiotou, M., Katafygiotou, M., Mazroei, A., Kaushik, A., Elsarrag, E., 2016. Impact of Indoor Environmental Quality on Occupant Well-being and Comfort: A Review of the Literature. International Journal of Sustainable Built Environment, Volume 5(1), pp. 1-11

Baqutaya, S., Ariffin, A.S., Raji, F., 2016. Affordable Housing Policy: Issues and Challenges among Middle-income Groups. International Journal of Social Science and Humanity, Volume 6(6), pp. 433-436

Centres for Disease Control and Prevention (CDC), 2013. Overview, Indoor Environmental Quality. The National Institute for Occupational Safety and Health (NIOSH)

Crump, D., 2011. Climate Change - Health Impacts Due to Changes in the Indoor Environment Research Needs. Web Report W28. Bedfordshire, Cranfield: Institute of Environment and Health

Eleventh Malaysia Plan, 2015. Eleventh Malaysia Plan, 2016-2020: Anchoring Growth on People. Putrajaya: Percetakan Nasional Malaysia Berhad 
Frontczak, M., Wargocki, P., 2011. Literature Survey on How Different Factors Influence Human Comfort in Indoor Environments. Building and Environment, Volume 46, pp. 922 937

Haghighat, F., Donnini, G., 1999. Impact of Psycho-social Factors on Perception of the Indoor Air Environment Studies in 12 Office Buildings. Building and Environment, Volume 34(4), pp. 479-503

Hashim, Z.A., 2010. House Price and Affordability in Housing in Malaysia. Akademika (Academic), Volume 78, pp. 37-46

Heiselberg, P., Bjørn, E., Nielsen, P.V., 2001. Impact of Open Windows on Room Air Flow and Thermal Comfort. International Journal of Ventilation, Volume 1(2), pp. 91-100

Houk, M., Koutsomarkou, J., Scantamburlo, M., Toscis, I., 2015. Sustainable Regeneration in Urban Areas, URBACT II, April 2015. European Union: URB ACT

Institute of Medicine, 2011. Climate change, the Indoor Environment, and Health. Washington, DC: The National Academies Press

Kamaruzzaman, S.N., Egbu, C.O., Zawawi, E.M.A., Ali, A.S., Che-Ani, A.I., 2011. The Effect of Indoor Environmental Quality on Occupants' Perception of Performance: A Case Study of Refurbished Historic Buildings in Malaysia. Energy and Buildings, Volume 43(2-3), 407-413

Kolleeny, F.J., 2003. Designing for Well-being: Environments that Enhance the Quality of Life. Architectural Record, Volume 191(11), pp. 90-118

Lai, A.C.K., Mui, K.W., Wong, L.T., Law, L.Y., 2009. An Evaluation Model for Indoor Environmental Quality (IEQ) Acceptance in Residential Buildings. Energy Building, Volume 41(9), pp. 930-936

Martellotta, F., Simone, A., Crociata, S. D., D’Alba, M., 2016. Global Comfort and indoor Environment Quality Attributes for Workers of a Hypermarket in Southern Italy. Building and Environment, Volume 95: pp. 355-364

Menshawy, E.A., Shafik, S., Khedr, F., 2016. Affordable Housing as a Method for Informal Settlements Sustainable Upgrading. Procedia-Social and Behavioural Sciences, Volume 223, pp. 126-133

Musa, A.R., Tawil, N.M., Sood, S.M., Che-Ani, A.I., Hamzah, N., Basri, H., 2011. Constructing Formulation of Affordable Green Home for Middle Income Group. Procedia Engineering, Volume 20, pp. 466-473

Nimlyat, P.S., Kandar, M.Z., 2015. Appraisal of Indoor Environmental Quality (IEQ) in Health Care Facilities: A Literature Review. Cities and Society, Volume 17, pp. 66-68

Pekkonen, M., Du, A.L., Skön, J.-P., Raatikainen, M., Haverinen-Shaughnessya, U., 2015. The Influence of Tenure Status on Housing Satisfaction and Indoor Environmental Quality in Finnish Apartment Buildings. Building and Environment, Volume 89, pp.134-140

Persily, A., 2015. Challenges in Developing Ventilation and Indoor Air Quality Standards: The Story of ASHRAE Standard 62. Building and Environment, Volume 91, pp. 61-69

Sarbu, L., Sebarchievici, C., 2013. Aspects of the Indoor Environmental Quality Assessment in Buildings. Energy and Buildings, Volume 60, pp. $410-419$

Tenth Malaysia Plan, 2011. Tenth Malaysia Plan, 2011-2015. Putrajaya: The Economic Planning Unit

Turunen, M., Toyinbo, O., Putus, T., Nevalainen, A., 2014. Indoor Environmental Quality in School Buildings, and the Health and Wellbeing of Students. International Journal of Hygiene and Environmental Health, Volume 217(7), pp. 733-739

United States Environmental Protection Agency (EPA), 1991. Indoor Air Facts No. 4 (Revised): Sick Building Syndrome. Research and Development. Washington D.C: US

United States Green Building Council, 2002. LEED ${ }^{\text {TM }}$ Green Building Rating System for New Construction and Major Renovations (LEED-NC) 
Vardoulakis, S., Dimitroulopoulou, C., Thornes, J., Lai, K.-M., Taylor, J., Myers, I., Heaviside, C., Mavrogianni, A., Shrubsole, C., Chalabi, Z., Davies, M, Wilkinson, P., 2015. Review Article Impact of Climate Change on the Domestic Indoor Environment and Associated Health Risks in the UK. Environment International, Volume 85, pp. 299-313

Willich, S.N., Wegscheider, K., Stallmann, M., Keil, T., 2006. Noise Burden and the Risk of Myocardial Infraction. European Heart Journal, Volume 27(3), pp. 276-282

Winston, N., 2008. Urban Regeneration for Sustainable Development: The Role of Sustainable Housing?. European Planing Studies, Volume 17(12), pp. 1781-1796 